\title{
Impact Assessment of Party Members and Cadres' Modern Distance Education Websites Based on Web Metrics
}

\author{
Lei Chen \\ Institute of Information on Science and Technology of Agriculture, Beijing Academy of agriculture and forestry Sciences. \\ The Research Center of Beijing Engineering Technology for Rural Remote Information Service, BeiJing, 100097, China
}

\begin{abstract}
Nowadays impact assessment of websites based on web metrics has been growing, and is leading a new trend in quantitative analysis. Based on prior efforts in laying theoretical foundations, this study examined 44 provincial party members and cadres' modern distance education websites in China. In order to look for a comprehensive impact measurement of modern distance education websites, the researcher collected the numbers of links and traffic data on each website. This study reported the following discoveries: 1) Website assessment methods based on link indexes or traffic indexes or Delphi expert scoring were effective. Web metrics based impact assessment was scientific to some extent and could be used to evaluate distance education websites.2) Affected by the statistical range and algorithm, there was a big difference between link index and traffic index ranking.3) The video shown held most of web pages in some party members and cadres' distance education websites, which largely limited its influence on the internet. Based on these findings, this study thought that the lower-order websites should be strengthening the content of the network information resources and improving organization level of the internal information, so that visitors would have been got more useful information. At the end, this study discussed the ideal situation of impact assessment, possible study errors, and future work needed.
\end{abstract}

Keywords- party members and cadres' modern distance education; impact assessment; web metrics; link analysis; traffic analysis.

\section{INTRODUCTION}

For published materials, impact assessment of party members and cadres' modern distance education websites is little sign of it. Impact assessment of websites based on web metrics has been growing, and is leading a new trend in quantitative analysis [1]. Based on software and other non artificial direct intervention approach, this study collected quantitative index to reflect the party members and cadres' modern distance education websites influence. These indicators could reflect the network operation characteristics and user characteristics reflect on cyber source distribution and user level influence.

\section{RESEARCH OBJECTS AND METHODS}

\section{A. Research objects}

This study adopted the non-randomized sampling method. To make sure each province or autonomous region had 1 provincial website, including in the modern distance education of party members and cadres, this study finally selected 44 sites of impact evaluation. The distribution of websites surveyed were: the Northeast 3 (6.8\%), North China 11 (25\%), East China 10 (22.7\%), the Northwest 6 (13.6\%), Southwest China 5 (11.4\%), central China 4 (9.1\%), South China 4 (9.1\%), the central site1 (2.3\%).

\section{B. Research indexes}

According to the related theories, website impact assessment mainly come from two aspects: the link analysis and traffic analysis. Link indexes mainly include number of pages, total number of links, home page of links, reverse link number. Traffic indexes include the number of users and page views, for evaluation websites application level and ability of radiation on the user level.

This study chose the network measurement index:

(1)Link index

i)Number of pages: the total number of the site webpage what is searched by search engine. Although there is a certain error between the actual total number and metrical total number, the index has the relative significance in the statistical analysis.

ii)Total number of links: The link to the site of the total number of webpage what is searched by search engine[2].

iii) Home page of links: The total number of webpage link to the website home page what is searched by search engine.

iv)Reverse link number: From the Alexa statistics, other stations in the network of their own site cast a vote of support. If more than one page links from the same site, will record only once.

(2)Traffic index

Application to the traffic indexes in this study have:

i)Traffic rank: Comprehensive analysis on the website of the last three months of daily visits and page views.

ii)CN traffic rank: Web traffic in China.

iii) Per capita page views: The number of the last three on the average daily view pages.

\section{Data collection methods}

This study used the Google search engine, especially the advanced search function. Advanced Google search interface can automatically generate the corresponding retrieval, Google advanced search indexes and retrieval type as shown in table 1 (e.g. www.bjcc.gov.cn) .Traffic 
index directly query from the Alexa Chinese official website.

TABLE I. DATA COLLECTING METHOD BASED ON GOOGLE ADVANCED SEARCH(2014-4-23)

\begin{tabular}{llc}
\hline Index & Google retrieval & Score \\
\hline Number of pages & Site:www.bjcc.gov.cn & 376,000 \\
\hline $\begin{array}{l}\text { Total number of } \\
\text { links }\end{array}$ & www.bjcc.gov.cn & 463,000 \\
\hline Home page of links & Link:www.bjcc.gov.cn & 7,450 \\
\hline
\end{tabular}

\section{Data processing and analysis}

Network link index based on the Google and Alexa, as well as the traffic indicator data collection, were completed in April 23, 2014. For the Alexa traffic index, average 3 months recently selected. In this study, the collected data were analyzed by Excel2007 and Delphi method.

(1) Determining weights by Delphi expert consultation

The researcher selected 12 experts including science and technology information, the rural economy, distance education, information engineering, education management and other fields. Base on the modern distance education of party members and cadres website link index and traffic index, the researcher designed website expert consultation table. Fill in the email or onsite method, consultation table was sent to the advisory expert. In the first round of consultation, according to the degree of important indicators expert's score from low to high grade 7 were assigned 1-7. At the same time, experts commented themselves by expert self evaluation questionnaire. After the first round, the index system was adjusted to start the second round of consultation. Please experts to consider again each index, at the same time to the statistical results of the first round of the feedback reports for reference.

(2)The reliability of experts
The expert reliability is determined by the positive coefficient, authority coefficient and the degree of concentration of expertise [3].

i) The positive coefficient can be shown by the questionnaire recovery rate. Two rounds of expert positive coefficients were $100 \%$,it shown that there was a cooperative willingness heavily each other .

ii)The expert authority coefficient $(\mathrm{Cr})$ is determined by two factors: One is the basis for the expert judgment $(\mathrm{Ca})$;Another is the expert familiarity with the problem(Cs).

Expressed in a formula, this can be written as follows: $\mathrm{Cr}$ $=(\mathrm{Ca}+\mathrm{Cs}) / 2$. Expert judgment was divided into theoretical analysis (coefficient $0.3,0.2,0.1$ ), practical experience (coefficient $0.5,0.4,0.3$ ), domestic and foreign counterparts to understand (coefficient 0.1 ) 和 intuition (coefficient 0.1 ).

The first and second rounds of expert authority coefficient were 0.82 and 0.83 . This shown that the degree of authority the evaluation content was high and the results were reliable

TABLE II. EVALUATION STANDARD OF EXPERT AUTHORITY COEFFICIENT

\begin{tabular}{cccc}
\hline $\begin{array}{c}\text { Standard } \\
\text { of influence } \\
\text { degree }\end{array}$ & $\begin{array}{c}\text { The sum of } \\
\text { the coefficients }\end{array}$ & $\begin{array}{c}\text { Standard } \\
\text { of familiar } \\
\text { degree }\end{array}$ & Coefficient \\
\hline Great & 1 & Very & 0.9 \\
\hline Common & 0.8 & Relatively & 0.7 \\
\hline Small & 0.6 & Know & 0.5 \\
\hline & Common & 0.3 \\
\hline & Less & 0.1 \\
\hline & Little & 0.0 \\
\hline
\end{tabular}

iii) The degree of concentration of expertise reflects the concentration of the experts the opinions. After first round of expert consultation, only $\mathrm{CN}$ traffic rank coefficient of variation was greater than $20 \%$.After second round of consultation, the coefficient of variation was less than $20 \%$ by delete $\mathrm{CN}$ traffic rank index. This shown that the expert opinion tended to concentrate.

TABLE III. VALUATION RESULTS

\begin{tabular}{ccccccc}
\hline Index & $\begin{array}{c}\text { Number of } \\
\text { pages }\end{array}$ & $\begin{array}{c}\text { Total } \\
\text { number } \\
\text { of links }\end{array}$ & $\begin{array}{c}\text { Home page of } \\
\text { links }\end{array}$ & $\begin{array}{c}\text { Reverse } \\
\text { link } \\
\text { number }\end{array}$ & Traffic rank & $\begin{array}{c}\text { Page } \\
\text { views }\end{array}$ \\
\hline Weight & 0.28 & 0.14 & 0.1 & 0.05 & 0.24 & 0.19 \\
\hline Ranking & 6 & 3 & 2 & 1 & 5 & 4 \\
\hline
\end{tabular}

\section{RESUlTS}

(1)Valuation results

(2) Comprehensive score results

Based on the statistical results of web metrics and Delphi expert assignment method, the comprehensive score of influence table as follows (Table 4)

\section{DISCUSSION}

The result of impact assessment of website in addition to develop cyber source evaluation function, also can determine the frequency of cyber source importance and determine the core site, to help the mining characteristics of different site and reflect the differences in content distribution site impact force and user acceptance level [4].Impact assessment based on web metrics will help to find some experiences and problems of website construction and operation to guide website construction and network management.

Through the analysis of the ranking, we could get that there was a big difference between link index and traffic index ranking, repeat number has only two. The causes of the problem were:1) Alexa had no statistics to the traffic flow characteristics of sections of the site, for example avg. time on page and number of pages, it resulted that missing value was replaced by the $0 ; 2$ ) The inherent 
defects of search engine would affect the results of the study. Search engine was influenced by factors such as scope limitations and system fluctuations and the imperfect of algorithm, which would influence the accurate link index.

TABLE IV. SCORE BASED ON TRAFFiC CHARACTERISTICS AND LINK CHARACTERISTICS(TOP 10)

\begin{tabular}{|c|c|c|c|c|c|}
\hline Website address & Traffic score & Traffic rank & Website address & Link score & Link rank \\
\hline & & & http://www.sx-dj.gov.cn & & \\
\hline http://www.zhongyuanjq.gov.cn & 3376958.64 & 1 & & 22565327.4 & 1 \\
\hline http://www.njycjy.com.cn/ & 2486796.72 & 2 & http://www.zq-dj.gov.cn & 3291540.7 & 2 \\
\hline \multirow[t]{2}{*}{ http://www.71tv.net.cn } & 2287328.16 & 3 & http://www.qinghai.ngx.net.cn & 485832.06 & 3 \\
\hline & & & http://dj.zj.vnet.cn & & \\
\hline http://www.hebdj.gov.cn & 2159836.08 & 4 & & 378230.5 & 4 \\
\hline \multirow[t]{2}{*}{ http://www.jcqzw.com } & 2088741.12 & 5 & http://www.sd-taishan.gov.cn & 335880.2 & 5 \\
\hline & & & http://www.bjcc.gov.cn & & \\
\hline http://www.tjdjw.cn & 1456373.76 & 7 & http://www.xjkunlun.cn & 128472.8 & 7 \\
\hline http://www.lndj.gov.cn & 1324662.96 & 8 & http://www.ahxf.gov.cn & 116536.05 & 8 \\
\hline http://www.nmgdj.gov.cn & 1164450.48 & 9 & http://www.nmgdj.gov.cn & 79129.2 & 9 \\
\hline http://www.jsxf.gov.cn & 1024045.92 & 10 & http://www.hnredstar.gov.cn & 55496.5 & 10 \\
\hline
\end{tabular}

Some party members and cadres' distance education web sites were mainly to video programs which largely limits its influence on the internet. In all the chain, outside the chain of simple distance education website accounts for the proportion to be far less than the comprehensive party's construction sites which only including part of distance education video. The average level of the former was only $10 \%$ of the latter. Therefore, in order to improve influence websites, most of which is distance education video program, also need to add some comprehensive columns and content.

\section{V.CONCLUSIONS}

Website assessment methods based on link indexes or traffic indexes or Delphi expert scoring are effective. The three methods focus on different aspect of websites, and need to be combined for comprehensive analysis. At same time, the lower-order websites should strengthen the content of the network information resources and improve the comprehensive information ratio. On the other hand, the lower-order websites also need to improve organization level of the internal information to improve the site link efficiency. In this study, only the top 10 websites were rough control. The ideal situation is that all sample web sites evaluation results (or rank) are carried out correlation analysis, to obtain a more precise, more convincing conclusions. Future researchers can compare of the relationship between link characteristics index, traffic index and principal component factor.

\section{REFERENCES}

[1] Ingwersen,P.The calculation of web impact factors.Journal of Documentation, 54 (2) ,pp.236- 243,1998.

[2] Wang Hongxin, A link analysis of websites of provincial public libraries in China. Journal of Library Science in China, 31(157), pp. 86- 97, 2005.

[3] Chen Ling-ling,The Status and module design of presence of nursing information on grade-A tertiary hospital web sites.Master's degree thesis of Huazhong University of Science and Technology,pp.17,2010.

[4] Cao Mei \& Min Yu-Feng, Impact assessment of educational websites in China.Open Education Research, 17(6), pp.104-110, Dec 2011. 